\title{
Inventory and Routing Problem of Supply Chain under Carbon Emission Constraint
}

\author{
Jianhua Wang ${ }^{1, a^{*}}$, Xianfeng Huang ${ }^{1, b}$, Yingying Shang ${ }^{1, c}$ and Ting Cao ${ }^{1, d}$ \\ ${ }^{1}$ Management School, Jiangsu University, Zhenjiang, China \\ ajiannywang@163.com, bhuangxianfeng@ujs.edu.cn, '949338423@qq.com \\ d642607727@qq.com
}

\section{Keywords: Carbon emission; Supply chain; Inventory; Routing}

\begin{abstract}
Sustainable development requires supply chains to operate in a low carbon way, and the inventory and transportation decision in a supply chain has an important influence on its overall carbon emissions. Based on the cooperative concept of jointly managed inventory among the members, this paper takes the multi-period Inventory Routing Problem (IRP) of a two stage supply chain as the research object which has some different characteristics such as supplying transportation, heterogeneous vehicles and emission constraint from the existing researches, builds an Integer Linear Programming(ILP) model under carbon emission constraints for the problem firstly, and then does experiments and analyzes the results on an actual case, finds out that the carbon emissions of a supply chain can be reduced greatly by jointly managing inventory and optimizing transportation routes at the expense of a small operating cost increase. The research results also provide some valuable implications for the low carbon improvement of supply chains.
\end{abstract}

\section{Introduction}

At present, environmental problems such as global warming and sea level rising threaten the survival of mankind. Developing a low carbon economy to curb climate change is becoming the common mission of all humankind ${ }^{[1]}$. Intergovernmental Panel on Climate Change (IPCC) presents that in order to prevent global warming and climate change, GHG emissions should be reduced by $50 \%$ of their 1990 levels by $2050^{[2]}$, and estimates an increase of $1.8-4^{\circ} \mathrm{C}$ in Earth's temperature by the end of this century because of the increased GHGs, such as carbon dioxide $\left(\mathrm{CO}_{2}\right)$, methane and nitrous oxide ${ }^{[3]}$. The warning information has inspired a worldwide debate about GHG emission reduction targets and regulations. Many countries and governments have accepted the premise that it is urgent to put policies into action, and have already set some specific targets. For example, through its European Climate Change Program, the European Union aims to reduce its GHG emissions by at least $20 \%$ by 2020 compared to 1990 levels $^{[4]}$. During the high-level segment of the Warsaw Climate Change Conference on Nov. 20, 2015, China promised to step up its efforts to address climate change in a bid to achieve the target of reducing $\mathrm{CO}_{2}$ emissions per unit of GDP by 40 to 45 percent by 2020 from the 2005 levels.

As a main form of economic operation, the supply chain has obligations and responsibilities to take effective actions for saving its energy consumption and reducing its carbon emission. Low carbon supply chain management which integrates green, low carbon, environmental protection concepts and technologies into the traditional supply chain management has got more and more attentions in both academia and industry, and creates many good ideas and methods to promote and help industries to reduce the impact of its operations on the environment ${ }^{[5-8]}$.

Globalization, with its increasing industrial trend towards outsourcing, has caused transportation to become the most visible sector that has increased GHG emissions over the last two decades. According to the EU reports, the total GHG emission by transportation is about $20.3 \%$ of the whole global carbon emission ${ }^{[9]}$. Transportation activities are therefore one of the primary contributors to global warming, and lead to the recent expansion of green logistics investigating as a subset of the green supply chain ${ }^{[10,11]}$. A comprehensive review of the studies on green logistics can be found in ${ }^{12]}$. Logistics is now widely recognized as value-adding components in organizations. The primary 
objective of logistics is to coordinate activities such as freight transportation, storage, inventory management and materials handling. One of the well-known topics typically addressed in this field is the Inventory Routing Problem (IRP).

The IRP is to determine simultaneously the optimal inventory control strategy and vehicle schedules to minimize the supply chain's total $\operatorname{cost}^{[13]}$. In the past, this cost has been assessed solely in economic terms. Due to the increasing environmental concerns, companies must better account for the external costs of logistics associated with global warming, air pollution, noise, vibrations and accidents ${ }^{[14,15]}$. This paper sets up a mathematical model for a multi-period IRP of a supply chain by considering the carbon emission constraint, and makes numerical experiments to analyze the influence of the carbon emission on the optimal inventory and routing decisions, and presents some management suggestions according to the exprements' results.

\section{Problem Description}

This paper studies the IRP of a supply chain which includes multiple suppliers and one assembly Factory $(F)$, each of the suppliers supplies one kind of part for the $F$ to assembly the final product for selling. Due to the limited space and the lean production management style, the $\mathrm{F}$ wants as few as possible to store the parts which could prevent from the occurrence of negative consequences such as long setup time, high inventory cost and parts loss. In order to achieve the low storage level, the factory calculates its next period's demand quantity for each kind of parts according to the sale orders and forecasting of the final product firstly, and then the 3rd party logistic company (3PL) organizes its vehicles to pick up the demanded parts from corresponding suppliers and ship to the Factory according to optimal routes which start and end at the 3PL. The vehicles can transport a kind of part from its supplier to the Factory directly or transship the part to store at another supplier for waiting a next transportation. The 3PL has many type vehicles with different capacities, carbon emission indexes, and fixed/variable transportation cost rates.

The research includes two objectives. One is to model and solve the IRP of the supply chain, which is to find the best configuration of the fleets, routes, pickups and transshipments in each period which minimizes the total cost of the supply chain including the transportation cost and storage cost, while satisfying some constraints. The other is to analyze the similarities and differences between the IRP with emission constraints and the IRP without emission constraints.

The IRP uses the following notation:

\section{Index Notations:}

$i, j$ : index of the companies in the supply chain, $i, j \in[0,1,2, \cdots, P+1]$, where node 0 represents the

3PL, node $\mathrm{P}+1$ represents the $\mathrm{F}$, others represent the suppliers

$k$ : index of the vehicle, $k=1,2, \ldots, K$

$t$ : index of the time periods, $t=1,2, \ldots, T$

\section{Input Parameters:}

$D_{p t}$ : demand quantity for part $p(p=1,2, \ldots, P)$ by the $\mathrm{F}$ in the period of $t$ to assembly final product

$d_{i j}$ : distances between nodes $i$ and $j$

$\alpha_{k}, \beta_{k}$ : fixed/variable transportation cost of the $k$ th vehicle

$V_{k}:$ maximum capacity of the $k$ th vehicle

$h_{i p}:$ unit storage cost of part $\mathrm{p}$ at node $i$ for one period

$Q_{i p t}$ : storage quantity of part $\mathrm{p}$ at node $i$ at the end of period $t$

$Q_{i p 0}$ : initial storage quantity of part $p$ at node $i$ at the begin of the $1^{\text {st }}$ period, where

$Q_{i p 0}=\left\{\begin{array}{cc}\sum_{t=1}^{T} D_{p t}, & i=p=1,2, \ldots, P \\ 0 & \text { else }\end{array}\right.$

$g_{k}$ : the GHG emission amount of the $k$ th vehicle at unit transporting distance 
$\theta_{g h g}:$ the GHG emission upper limit in each period for the whole supply chain.

\section{Decision Variables:}

$x_{i j k t}:$ a binary variable that determines if $\operatorname{arc}(i, j)$ is visited by the $k^{\text {th }}$ vehicle in period $t$;

$y_{i p t}$ : the quantity of part $p$ picked up from node $i$ in period t by all of the vehicles

$z_{i p t}$ : the quantity of part $p$ unloaded to node $i$ in period $t$ by all of the vehicles

$q_{i j p k t}$ : the quantity of part $p$ transported by vehicle $k$ through $\operatorname{arc}(i, j)$ in period $t$.

\section{Mathematic Formulation}

This paper optimizes the inventory and routing configuration of a multi-period supply chain under carbon emission constraints, the objective is to minimize the sum cost of transportation and inventory while it meets some constraints, so the ILP model formulation is following:

$$
\begin{aligned}
\operatorname{Min}^{T C} & =\sum_{t=1}^{T} \sum_{k=1}^{K} \sum_{j=1}^{P} \alpha_{k} x_{0 j k t}+\sum_{t=1}^{T} \sum_{k=1}^{K} \sum_{i=0}^{P+1} \sum_{j=0}^{P+1} \beta_{k} x_{i j k t} d_{i j} \\
& +\sum_{t=1}^{T} \sum_{i=1}^{P+1} \sum_{p=1}^{P} h_{i p} Q_{i p t}
\end{aligned}
$$

Subject to:

$$
\begin{aligned}
& \sum_{i=0}^{P+1} x_{i j k t}=\sum_{i=0}^{P+1} x_{j i^{\prime} k t} \leq 1 \quad \forall j, k, t \\
& \sum_{i=1}^{P+1} x_{i j k t} \leq \sum_{i=1}^{P} x_{0 i^{\prime} k t} \quad \forall j \neq P+1, k, t \\
& x_{(P+1) j k t}=0 \quad \forall j, k, t \\
& x_{i 0 k t}=0 \quad \forall i, k, t \\
& x_{0(P+1) k t}=0 \quad \forall k, t \\
& \sum_{i, j \in S} x_{i j k t} \leq|S|-1 \quad \forall k, t \\
& \sum_{p=1}^{P} q_{i j p k t} \leq V_{k} x_{i j k t} \quad \forall i, j, k, t \\
& \sum_{i=0}^{P+1} \sum_{k=1}^{K} x_{i j k t} q_{i j p k t}+y_{j p t}-z_{j p t}=\sum_{i=0}^{P+1} \sum_{k=1}^{K} x_{j i^{\prime} k t} q_{j i^{\prime} p k t} \quad \forall j, p, t \\
& Q_{i p t}=Q_{i p(t-1)}-y_{i p t}+z_{i p t} \quad \forall i \neq 0, i \neq P+1, p, t \\
& Q_{(P+1) p t}=Q_{(P+1) p(t-1)}+z_{(P+1) p t}-D_{p t} \quad \forall p, t \\
& Q_{0 p t}=0 \quad \forall p, t \\
& \sum_{t=1}^{n} z_{(P+1) p t} \geq \sum_{t=1}^{n} D_{p t} \quad \forall n, p \\
& Q_{i p t} \geq 0 \quad \forall i, p, t \\
& \sum_{i=0}^{P+1} \sum_{j=0}^{P+1} \sum_{k=1}^{K} x_{i j k t} d_{i j} g h g_{k} \leq \theta_{g h g} \quad \forall t \\
& x_{i j k t} \in\{0,1\} \quad \forall i, j, k, t \\
& y_{i p t}, z_{i p t}, q_{i j p k t} \geq 0, \text { integer } \\
& E q .(1) i s t
\end{aligned}
$$

Eq. (1) is the objective function of the model that aims to minimize the total supply chain cost, including the fix and variable transportation costs as well as the inventory cost.

Constraints (2)-(7) are routing rules for all of the vehicles. Constraint (2) ensures the coming times of a specific vehicle to a node must equal to the leaving times of that vehicle from that node in a single time period, and the times is not larger than 1. Constraint (3) ensures the vehicle must start from the 3PL if the vehicle is used. Constraint (4) ensures vehicles don't drive from the F to any of the suppliers in all of the time periods. Constraint (5) ensures vehicles don't drive back from any of the suppliers to the 3PL directly. Constraint (6) ensures vehicles don't drive from the 
3PL to the F directly. Constraint (7) ensures vehicles don't form a loop route among the suppliers and must unload parts to the F.

Constraint (8) imposes the capacity constraint of each vehicle. Constraint (9) states the quantity of one part on a vehicle which leaves a node is equal to the quantity of the part on the vehicle which comes to the node pluses/minus the loaded/unloaded quantity of the part at this node.

Constraints (10)-(14) are the inventory level constraints for each node. Constraint (10) guarantees the stock quantity at the present period is equal to the previous period stock subtracts the shipping out quantity and adds the shipping in quantity at the present period. Constraint (11) guarantees the part stock changing at the F in two adjacent periods. Constraint (12) shows the 3PL don't store any part. Constraint (13) ensures the total quantity of one part shipped to the $\mathrm{F}$ at the end of any period is not less than the demand quantity of the part by the $\mathrm{F}$ for all of the previous periods. Constraint (14) is nonnegative constraint.

Constraint (15) limits the sum amount of GHG emission by all of the vehicles in each period to a given level. This model can be used to solve the IRP without GHG constraint by getting rid of this constraint, but to solve the IRP with GHG constraint by considering this constraint.

Constraint (16) and (17) define the variable types.

The IRP is an integer linear programming (ILP) problem in essence, which could be solved by using OR software based on proper mathematic model while the model size is not very large.

\section{Numerical Example}

In the following, a simplified real vehicle and routing problem of a manufacturing supply chain is taken as an example to evaluate the efficiency of the model, and contrast the differences between the solutions of considering carbon emission and that of without considering carbon emission.

Details of the Example. The supply process of five parts in two neighboring periods for a car maker (F) at Wuhu China is analyzed. The demand quantity of each kind part in each period by the Factory are shown in Table 1, the vehicle information are shown in Table 2, the distances among the members in the supply chain are shown in Table 3. The holding costs for all of the suppliers are 5 Y/unit.period while that of the $\mathrm{F}$ is $20 \mathrm{RMB} /$ unit.period. In the case of considering the carbon emission constraint, the emission upbound in the constraint (15) is set to $950 \mathrm{~kg}$. while without considering the carbon emission constraint, the constraint (15) is abandoned. For the whole problem, it is assumed that the specific part's inventory in each supplier is not less than the demand quantity for the two periods by the car maker.

Table 1 part demand quantity in different periods by the assembly plant

\begin{tabular}{|c|c|c|c|c|c|}
\hline $\begin{array}{c}\text { part } \\
\text { period }\end{array}$ & $\mathbf{1}$ & $\mathbf{2}$ & $\mathbf{3}$ & $\mathbf{4}$ & $\mathbf{5}$ \\
\hline $\mathbf{1}$ & 0 & 500 & 0 & 300 & 300 \\
\hline $\mathbf{2}$ & 400 & 0 & 300 & 200 & 100 \\
\hline
\end{tabular}

Table 2 Vehicle information of 3PL

\begin{tabular}{|c|c|c|c|c|}
\hline $\begin{array}{c}\text { Vehicle } \\
\boldsymbol{k}\end{array}$ & $\alpha_{k}(\mathbf{R M B})$ & $\beta_{k}(\mathbf{R M B} / \mathbf{k m})$ & $V_{k}(\mathbf{u n i t})$ & $g_{k}(\mathbf{k g} / \mathbf{k m})$ \\
\hline $\mathbf{1}$ & 500 & 8 & 700 & 1.2 \\
\hline $\mathbf{2}$ & 500 & 8 & 700 & 1.2 \\
\hline $\mathbf{3}$ & 1000 & 6 & 1000 & 4.8 \\
\hline $\mathbf{4}$ & 1500 & 4 & 1300 & 7.6 \\
\hline
\end{tabular}


Table 3 Distances among the supply chain members $(\mathrm{km})$

\begin{tabular}{|c|c|c|c|c|c|c|c|}
\hline & 3PL & S1 & S2 & S3 & S4 & S5 & F \\
\hline 3PL & 0 & 60 & 106 & 172 & 75 & 77 & 50 \\
\hline S1 & 60 & 0 & 56 & 184 & 128 & 114 & 44 \\
\hline S2 & 106 & 56 & 0 & 180 & 157 & 170 & 99 \\
\hline S3 & 172 & 184 & 180 & 0 & 132 & 240 & 220 \\
\hline S4 & 75 & 128 & 157 & 132 & 0 & 125 & 128 \\
\hline S5 & 77 & 114 & 170 & 240 & 125 & 0 & 73 \\
\hline F & 50 & 44 & 99 & 220 & 128 & 73 & 0 \\
\hline
\end{tabular}

Results Analysis.By using Lingo11 to solve the IRP model, and the optimal solutions with GHG constraint and without GHG constraint are shown in Fig. 1. The operational cost for the solution without GHG constraint is $11361 \mathrm{RMB}$, and the carbon emission for that solution is $6234 \mathrm{~kg}$. In contrast, the operational cost for the solution with GHG constraint is $15732 \mathrm{RMB}$ which is $27.8 \%$ higher than that of without GHG constraint, and the carbon emission is $1910 \mathrm{~kg}$ which is $69.4 \%$ lower than that of without GHG constraint. From these results, a conclusion could be deduced that the supply chain GHG emission would reduce greatly by less operational cost increase. Beyond that, there also exist some differences in the routes and vehicles' schedules of the two situations of the IRP. The solutions are described in detail as the following.

The Detail Solution of the IRP with GHG Constraint. The optimal solution with GHG constraint sends the vehicle $\mathrm{K} 1$ and $\mathrm{K} 2$ in period 1 and the vehicle $\mathrm{K} 3$ in period 2 for transporting parts.

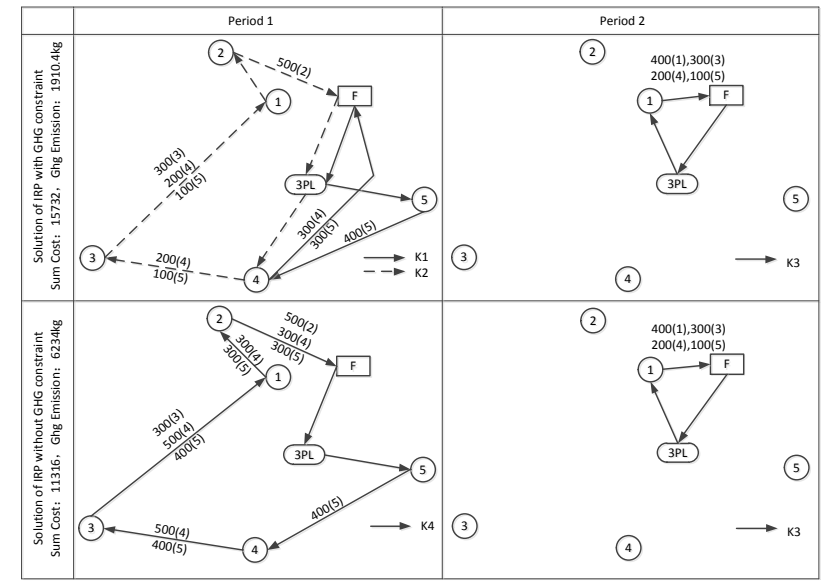

Figure 1. Optimal Solutions of the IRP with and without GHG constraint.

Note: Numbers on a route represent the part and its quantity loaded by a vehicle on the route, for example, the numbers on the route between supplier 3 and supplier 4 means that a vehicle loads 500 pieces of part 4 and 400 pieces of part5 in the solution of IRP without GHG constraint at period 1.

The routing processes of K1 are: (1) travel to the 5th supplier from 3PL to load 400 pieces of part 5; (2) travel to the $4^{\text {th }}$ supplier to unload 100 pieces of part 5 and load 300 pieces of part 4 , and then transport the 300 pieces of part 4 and the 300 pieces of part 5 to the F; (3) unload all of the part to the F; (4) go back to 3PL.

The routing processes of K2 are: (1) travel to the $4^{\text {th }}$ supplier from 3PL to load 200 pieces of part 4 and 100 pieces of part 5 which are unloaded by K1; (2) travel to the $3^{\text {rd }}$ supplier to load 300 pieces of part 3, and transport the 300 pieces of part 3 and the 200 pieces of part 4 and the 100 pieces of part 5 to the $1^{\text {st }}$ supplier and unload them all to there; (3) travel at empty condition to the $2^{\text {nd }}$ supplier and load 500 pieces of part 2; (4) travel to the F and unload all of the 500 pieces of part 2; (5) go back to the 3PL. 
The routing processes of $\mathrm{K} 3$ in period 2 are: (1) travel to the $1^{\text {st }}$ supplier from 3PL to load all of the 400 pieces of part 1, the 300 pieces of part 3, the 200 pieces of part 4 and the 100 pieces of part 5 ; (2) travel to the F from the $1^{\text {st }}$ supplier and unload all of its loads; (3) go back to the 3PL.

The Detail Solution of the VRP without GHG Constraint. The optimal solution without GHG constraint sends the vehicle $\mathrm{K} 4$ in period 1 and the vehicle $\mathrm{K} 3$ in period 2 for transporting parts respectively.

The routing processes of K4 are: (1) travel to the $5^{\text {th }}$ supplier from 3PL to load 400 pieces of part 5 ; (2) travel to the $4^{\text {th }}$ supplier to load 500 pieces of part 4 ; (3) travel to the $3^{\text {rd }}$ supplier to load 300 pieces of part 3 ; (4) transport all of the three kinds of parts to the $1^{\text {st }}$ supplier, and unload 300 pieces of part 3, 200 pieces of part 4 and 100 pieces of part 5 to this supplier; (5) travel to the $2^{\text {nd }}$ supplier and load 500 pieces of part2; (6) travel to the $F$ with 500 pieces of part2, 300 pieces of part 4 and 300 pieces of part 5, and unload all them at the F; (7) go back to the 3PL.

The processes of $\mathrm{K} 3$ in period 2 are ad same as that of the solution with GHG constraint.

From the above details of the two solutions in Figure 1, some managerial implications could be derived. (1) In different stock cost rate situation, it has benifit to store parts in the places with lower stock cost rate, so neither of the two optimal solutions transport the second period demand in the first period. (2) It can save the whole transportation cost to transship parts in far suppliers to near suppliers and store at there for waiting the next period transportation. This implication shows that jointly managing inventory among a supply chain maybe a good idea to reduce its operational cost. (3) When the GHG emission is one of the decision factors, it is wise to choose greener vehicles to transport parts even the vehicles' capacity is smaller and its variable transporting cost is higher. When the running cost is the only decision objective, it is wise to choose bigger and cheaper vehicles to transport parts. So in the period 1 solution with GHG constraint, two greener and smaller vehicles, $\mathrm{K} 1$ and $\mathrm{K} 2$, are chosen to transport parts, but the bigger and cheaper vehicle $\mathrm{K} 4$ is chosen to transport parts in the period 1 solution without GHG constraint. This implication shows that decisions of vehicles and its routes could be led to different economic and environmental results when there have many green level vehicles.

From all of these implications, one suggestion is presented that the supply chain members should run and optimize the inventory and routing problem carefully and efficiently so as to obtain the good benefits of both the economic and the environment.

\section{Summary and Conclusion}

This paper deals with the inventory and routing problem(IRP) for a two stage supply chain which has many specific characteristics, such as the carbon emission constraint and heterogeneous vehicles. To represent the problem mathematically, an integer linear programming model, which could be modeled and solved by OR softwares easily when the problem scale is not very large, is set up. Then, computational experiments are made on a simplified manufacturing supply chain, and the results show that the optimal solution for the IRP with carbon emission constraint and without carbon emission constraint are different. In particular, reducing the carbon emission leads to more operational cost of the supply chain, but the decreasing rate of carbon emission is greater than the rising rate of operation cost. Furthermore, some useful suggestions could be found for promoting a supply chain to run on a low carbon level: (1) driving the 3PL to adopt more carbon efficient vehicles by the key corporation in a supply chain or increasing the carbon trading price by the appropriate authorities could realize the low carbon supply chain. (2) Taking actions to reduce storage costs or designing coordination mechanism to carry out jointly managing inventory could reduce both the operational cost and carbon emission. (3) optimizing vehicle routes and managing stock collaboratively are effective methods to set up low carbon operating schedules.

\section{Future Studies}

To conduct more experiments to investigate the relationships among the two objectives and the four kinds of the SC parameters, such as stock costs of SC members, transportation costs of vehicles, 
carbon emission indexes of vehicles and the SC structure, and then more valuable rules would be found, which are more near to complex supply chain configurations.

As the development of the economic globalization and SC management techniques, the structure of a supply chain is becoming large and complex. In order to solve a large scale IRP of green supply chains, it is indeed necessary to develop more effective algorithms based on heuristics or swarm intelligence for helping the SC managers to run the SC economically and environmental friendly because an IRP is NP-hard.

\section{Acknowledgement}

The study is supported by National Natural Science Foundation of China(no. 71273118, no. 71273120), Jiangsu provincial philosophy and social science research project (no. 2015SJB835), Excellent Talent Foundation of Jiangsu University(No. 11JDG006)

\section{References}

[1] J.-B. Sheu and W. K. Talley, "Green Supply Chain Management: Trends, Challenges, and Solutions," Transportation Research Part E: Logistics and Transportation Review, vol. 47, pp. 791-792, 11// 2011.

[2] T. Barker, I. Bashmakov, L. Bernstein, J. Bogner, and P. Bosch, Climate Change 2007: Mitigation of Climate Change. Contribution of Working Group III to the Fourth Assessment Report of the Intergovernmental Panel on Climate Change. Cambridge, United Kingdom: Cambridge University Press, 2007.

[3] L. Meyer and S. Brinkman, "IPCC, 2014: Climate Change 2014: Synthesis Report," Geneva, Switzerland2014.

[4] EEA, "Annual European Union greenhouse gas inventory 1990-2008 and inventory report 2010," European Environment Agency2010.

[5] T. Abdallah, A. Farhat, A. Diabat, and S. Kennedy, "Green supply chains with carbon trading and environmental sourcing: Formulation and life cycle assessment," Applied Mathematical Modelling, vol. 36, pp. 4271-4285, 2012.

[6] R. Hoggett, "Technology scale and supply chains in a secure, affordable and low carbon energy transition," Applied Energy, vol. 123, pp. 296-306, 6/15/ 2014.

[7] G. Palak, S. D. Ekşioğlu, and J. Geunes, "Analyzing the impacts of carbon regulatory mechanisms on supplier and mode selection decisions: An application to a biofuel supply chain," International Journal of Production Economics, vol. 154, pp. 198-216, 2014.

[8] R. He, Y. Xiong, and Z. Lin, "Carbon emissions in a dual channel closed loop supply chain: the impact of consumer free riding behavior," Journal of Cleaner Production, vol. 134, Part A, pp. 384-394, 2016.

[9] EC, "A European Strategy for Low-Emission Mobility," European Commission, Brussels2016.

[10]M. Azadi, A. Shabani, M. Khodakarami, and R. Farzipoor Saen, "Planning in feasible region by two-stage target-setting DEA methods: An application in green supply chain management of public transportation service providers," Transportation Research Part E: Logistics and Transportation Review, vol. 70, pp. 324-338, 10// 2014.

[11]X. Chen and X. Wang, "Effects of carbon emission reduction policies on transportation mode selections with stochastic demand," Transportation Research Part E: Logistics and Transportation Review, vol. 90, pp. 196-205, 2016. 
[12]R. Dekker, J. Bloemhof, and I. Mallidis, "Operations Research for green logistics - An overview of aspects, issues, contributions and challenges," European Journal of Operational Research, vol. 219, pp. 671-679, 2012.

[13]C. Cheng, M. Qi, X. Wang, and YingZhang, "Multi-period inventory routing problem under carbon emission regulations," International Journal of Production Economics, pp. 263-275, 2016.

[14]D. Konur, "Carbon constrained integrated inventory control and truckload transportation with heterogeneous freight trucks," International Journal of Production Economics, pp. 268-279, 2014.

[15]S. Elhedhli and R. Merrick, "Green supply chain network design to reduce carbon emissions," Transportion Research Part D: Transport and Environment, vol. 17, pp. 370-379, 2012. 